\title{
Heparan sulfate functions are altered in the osteoarthritic cartilage
}

\author{
Sara Shamdani', Sandrine Chantepie', Camille Flageollet', Nadia Henni-Chebra', Yohann Jouan ${ }^{1,3}$, \\ Florent Eymard ${ }^{1,4}$, Eric Hay ${ }^{2,3}$, Martine Cohen-Solal ${ }^{5,2,3}$, Dulce Papy-Garcia', Xavier Chevalier ${ }^{1,4}$ and \\ Patricia Albanese ${ }^{1 *}$
}

\begin{abstract}
Background: Heparan sulfate (HS) proteoglycans (PG) may be found at the chondrocyte surface and in the pericellular cartilage matrix, and are involved in cell-cell and cell-matrix interactions. An important function of HS chains is to regulate cell fate through specific interactions with heparin-binding proteins (HBP) modulated by their complex sulfation pattern. Osteoarthritis $(\mathrm{OA})$ is a joint disorder characterized by the degradation of articular cartilaginous extracellular matrix. The aim of this study was to investigate HS structure and functions in osteoarthritic cartilages compared to normal cartilages (controls).

Methods: Glycosaminoglycans (GAG) were extracted from human macroscopically normal cartilages (controls, $n=$ 7) and (OA cartilages $n=11)$. HS were isolated and quantified using the DMMB quantification method. Their structure and functions were then compared using respectively a HPLC analysis and HBP binding tests and their phenotypic effects on murine chondrocytes were studied by RQ-PCR. Statistical analyzes were performed using a one-way ANOVA followed by a Dunnett's test or a $t$ test for pairwise comparisons.

Results: In OA, HS were characterized by increased sulfation levels compared to controls. Moreover, the capacity of these HS to bind HBP involved in the OA pathophysiological process such as FGF2 and VEGF was reduced. Chondroitin sulfates and keratan sulfates regulated these binding properties. Finally, HS from OA cartilages induced the mRNA levels of catabolic markers such as MMP3, MMP13, and TS4 and inhibited the mRNA levels of anabolic markers such as COL2, ACAN, SOX9, and VEGF in murine articular chondrocytes.

Conclusion: The sulfation of HS chains was increased in OA cartilages with changes in HBP binding properties and biological effects on chondrocyte phenotypes. Thus, modified HS present in altered cartilages could be a novel therapeutic target in OA.
\end{abstract}

Keywords: Heparan sulfate, Sulfation, Osteoarthritis, Cartilage matrix, Chondrocytes

\footnotetext{
* Correspondence: albanese@u-pec.fr

'Univ Paris Est Creteil, Gly-CRRET, Glycobiology Cell Growth Tissue Repair and

Regeneration Research Unit, Créteil F-94010, France

Full list of author information is available at the end of the article
}

\section{$\triangle B M C$}

(c) The Author(s). 2020 Open Access This article is licensed under a Creative Commons Attribution 4.0 International License, which permits use, sharing, adaptation, distribution and reproduction in any medium or format, as long as you give appropriate credit to the original author(s) and the source, provide a link to the Creative Commons licence, and indicate if changes were made. The images or other third party material in this article are included in the article's Creative Commons licence, unless indicated otherwise in a credit line to the material. If material is not included in the article's Creative Commons licence and your intended use is not permitted by statutory regulation or exceeds the permitted use, you will need to obtain permission directly from the copyright holder. To view a copy of this licence, visit http://creativecommons.org/licenses/by/4.0/ The Creative Commons Public Domain Dedication waiver (http://creativecommons.org/publicdomain/zero/1.0/) applies to the data made available in this article, unless otherwise stated in a credit line to the data. 


\section{Background}

Osteoarthritis (OA) is the most common disabling joint disorder and is associated with a high economic burden. It is characterized by joint cartilage degradation, subchondral bone remodeling, and synovitis [1]. A damaged articular cartilage has a poor capacity for self-repair and there is so far no efficient curative treatment available for OA [2]. The articular cartilage performs biomechanical functions within the joint, sustained by an extracellular matrix (ECM) very rich in fibrillar proteins such as collagens, and in proteoglycans such as aggrecan. As a result of ECM injuries or changes in ECM quality with aging, chondrocytes become hyper-activated. They secrete different degrading matrix enzymes and decrease anabolic activities, triggering their own hypertrophy and the mineralization process, that are characteristic stages of OA [3]. Among ECM components, glycosaminoglycans (GAG) are long anionic polysaccharides that form highly complex structures subdivided into four subfamilies according to their repeated disaccharide building blocks: heparan sulfates (HS), chondroitin sulfates (CS), keratan sulfates (KS), and hyaluronic acid (HA). The structural complexity of GAG is due to the heterogeneity of their disaccharide composition, their glycosidic linkages, and their various sulfation patterns. Sulfated GAG (HS, CS, and KS) are covalently bound to core proteins to form proteoglycans (PG), whereas nonsulfated HA remains free in the ECM.

Studies assessing cartilage ECM remodeling in aging and OA have mainly been focused on the main PG called aggrecan and on the structural and moisturizing functions of its CS and KS chains [4-6]. Indeed, a reduced size in and the loss of sulfated CS and KS chains alter the integrity and biomechanical properties of the cartilage matrix $[4,5]$. However, heparan sulfate proteoglycans (HSPG), including the syndecan and glypican families, are also present in the cartilage, but at lower concentrations [7]. HSPG are involved in the functional regulation of cell properties through their capacity to specifically interact with heparin-binding proteins (HBP), including growth and/or differentiation factors, cytokines, chemokines, morphogens, and enzymes [8]. This is mainly due to the complex structures of HS that vary in terms of sulfate and acetate group contents, and length of their sulfated domains. HS protect HBP from their proteolytic degradation and trigger their activities. They also provide matrix storage sites for HBP prior to their binding to cell surface components $[9,10]$. Therefore, fine alterations of HS structures affect their ability to regulate the activity of trophic factors on cell functions, leading to a potential loss of tissue function, as previously shown in aging $[11,12]$ or in various diseases $[13,14]$. Due to their low concentrations and to the difficulty in purifying them, only a few studies have assessed
HS structural evolution and their biological functions in the cartilage. The aim of this study was thus to assess HS structure and functions in OA cartilages compared to control cartilages.

\section{Methods}

Human cartilage samples and clinical characteristics

Cartilage explants were obtained from human subjects. All subjects provided their informed consent and a legal authorization was provided by the Ethics Committee of the Rheumatology Department of Henri Mondor Hospital (no. 07-34). Demographics and clinical data were collected (Table 1). Explants were taken from the knee of OA patients $(n=11)$ undergoing total knee replacement surgery. These OA explants originated from the femur (F), tibial plateau (TP), and patella (P) were sampled $1-4 \mathrm{~h}$ after ablation from the joint. Control explants $(n=7)$ were taken from a macroscopically normal cartilage part of the femoral head of control subjects after neck fracture. The extent of wear of all explants was assessed using the Kellgren-Lawrence grading system (0-4) [15], and explants were then immediately frozen at $-80^{\circ} \mathrm{C}$ until used. Patients were not involved in the design, conduct, reporting, and dissemination of the research.

\section{Extraction and quantification of GAG from articular cartilages}

GAG were extracted as previously described [11]. Briefly, freeze-dried samples were weighted, homogenized and suspended in digestion buffer $(50 \mathrm{mM}$ Tris- $\mathrm{HCl}, 10 \mathrm{mM}$ $\mathrm{NaCl}, 3 \mathrm{mM} \mathrm{MgCl}$, $1 \%$ Triton X-100, $\mathrm{pH}$ 7.9) to a final concentration of $50 \mathrm{mg}$ of tissue per $\mathrm{mL}$. Samples were incubated with proteinase K (Sigma-Aldrich, final concentration $100 \mu \mathrm{g} / \mathrm{mL}$ ) at $56^{\circ} \mathrm{C}$ for $24 \mathrm{~h}$, followed by enzyme inactivation at $90{ }^{\circ} \mathrm{C}$ for $30 \mathrm{~min}$. DNA was then digested with DNase I (Qiagen, $10 \mathrm{U} / \mathrm{mL}$ of sample) overnight at $37^{\circ} \mathrm{C}$. Samples were filtered (PALL life science ODM02C34) and centrifuged (12,000 rpm, $10 \mathrm{~min}$, at $\left.6{ }^{\circ} \mathrm{C}\right) . \mathrm{NaCl}$ was added to the filtrates at a final concentration of $4 \mathrm{M}$ and samples were stirred for $30 \mathrm{~min}$ at room temperature (RT). Samples were incubated with $10 \%$ TCA (Sigma-Aldrich), cooled at $4{ }^{\circ} \mathrm{C}$ for $15 \mathrm{~min}$, and centrifuged $\left(12,000 \mathrm{rpm}, 10 \mathrm{~min}, 4{ }^{\circ} \mathrm{C}\right)$ and the supernatants were recovered. Lipids were eliminated by chloroform extraction (1:1) and centrifugation (12,000 $\left.\mathrm{rpm}, 10 \mathrm{~min}, 8^{\circ} \mathrm{C}\right)$. The aqueous fractions were dialyzed (Thermo scientific $3.500 \mathrm{MWCO}$ ) against a buffer (50 $\mathrm{mM}$ Tris, $50 \mathrm{mM}$ CH3COO-Na, $2 \mathrm{mM} \mathrm{CaCl}_{2}, \mathrm{pH} 7$ ) and then against pure $\mathrm{H}_{2} \mathrm{O}$. Samples were frozen at $-80{ }^{\circ} \mathrm{C}$ and freeze-dried. Finally, samples were re-suspended in pure $\mathrm{H}_{2} \mathrm{O}$ to a desired tissue weight $/ \mathrm{H}_{2} \mathrm{O}$ volume concentration and stored at $-20{ }^{\circ} \mathrm{C}$ until use. Extraction/ quantification quality controls (QC) were included in 
Table 1 Patient's clinical characteristics. Data is expressed as the mean \pm SEM of values from healthy control donors (CT) and osteoarthritis patients (OA) according to the gender (female (F), male (M)) and for all subjects

\begin{tabular}{|c|c|c|c|c|c|c|}
\hline Patients & CT & & & $O A$ & & \\
\hline Sex & $F$ & $M$ & All & $\mathbf{F}$ & $M$ & All \\
\hline Number & 6 & 1 & 7 & 5 & 6 & 11 \\
\hline Age (year) & $82 \pm 5$ & 88 & $83 \pm 4$ & $78 \pm 9$ & $74 \pm 6$ & $75 \pm 7$ \\
\hline Lenght $(\mathrm{cm})$ & $160 \pm 1$ & 178 & $166 \pm 8$ & $156 \pm 2$ & $178 \pm 3$ & $169 \pm 10$ \\
\hline Weight (kg) & $56 \pm 6$ & 95 & $64 \pm 12$ & $66 \pm 2$ & $97 \pm 16$ & $84 \pm 19$ \\
\hline \multicolumn{7}{|l|}{ OA severity } \\
\hline (K-L global) & $1.7 \pm 0.4$ & 1 & $1.6 \pm 0.5$ & $4 \pm 0$ & $4 \pm 0$ & $4 \pm 0$ \\
\hline Menopause & Yes & NC & & Yes & NC & \\
\hline Analgesics & NC & NC & NC & 0 & 3 & 3 \\
\hline AINS & NC & NC & NC & 0 & 1 & 1 \\
\hline Corticoid & NC & NC & NC & 1 & 0 & 1 \\
\hline Hyaluronic Acid & NC & NC & NC & 1 & 0 & 1 \\
\hline Period of symptoms (Year) & NC & $N C$ & NC & $12.5 \pm 2.5$ & $9 \pm 3$ & $10 \pm 2$ \\
\hline
\end{tabular}

OA severity was assessed using the Kellgren-Lawrence $(\mathrm{KL})$ radiographic classification of knee for OA: $0=$ normal, $1=$ doubtful, $2=$ minimal, $3=$ moderate and 4 = severe. NC not concerned, NSAID non-steroidal anti-inflammatory drugs

each extraction process, by spiking a known amount of GAG from some freeze-dried cartilage samples to calculate the GAG extraction yield.

To isolate GAG species, total GAG samples were diluted in glycanase digestion buffer. To isolate HS, keratanase $(2 \mathrm{mU} / \mathrm{mL}$; Amsbio PS170615) was added for $1 \mathrm{~h}$ at $37^{\circ} \mathrm{C}$, followed by chondroitinase $\mathrm{ABC}(300 \mathrm{mU} / \mathrm{mL}$, SIGMA C3667) for $1 \mathrm{~h}$ and $30 \mathrm{~min}$ at $37^{\circ} \mathrm{C}$. To isolate $\mathrm{CS}$, samples were incubated with keratanase and then a mix of heparitinases I, II, and III $(250 \mathrm{mU} / \mathrm{mL}$ for each, Iduron) was added overnight at $37^{\circ} \mathrm{C}$. To isolate $\mathrm{KS}$, samples were incubated with chondroitinase ABC (300 $\mathrm{mU} / \mathrm{mL}$, SIGMA C3667) for $1 \mathrm{~h}$ and $30 \mathrm{~min}$ at $37^{\circ} \mathrm{C}$ and then a mix of heparitinases I, II, and III $(250 \mathrm{mU} / \mathrm{mL}$ for each, Iduron) was added overnight at $37^{\circ} \mathrm{C}$.

\section{Dimethyl-methylene blue (DMMB) assay for quantification of sulfated GAG}

Sulfated GAG were quantified using the 1-9 dimethylmethylene blue (DMMB, Sigma-Aldrich) assay as previously described [16]. CS, KS, and HS were quantified in each sample after enzymatic and/or chemical reactions. QC for total digestion and GAG specificity were included by spiking samples with known amount of commercial CS, KS, or HS. CS were quantified after digestion with chondroitinase ABC (Sigma-Aldrich) as previously described [16]. HS were quantified after incubation with nitrous acid as previously described [16]. KS were quantified according to 2 strategies. First, HS and CS were digested with chondroitinase ABC (300 mU/ $\mathrm{mL}$ ) and a mix of heparitinases I, II, and III (Iduron, $250 \mathrm{mU} / \mathrm{ml}$ for each) for $1 \mathrm{~h}$ at $37^{\circ} \mathrm{C}$. The remaining
GAG corresponding to $\mathrm{KS}$ were quantified according to the DMMB protocol. In a second strategy, samples were incubated with keratanase $(2 \mathrm{mU} / \mathrm{mL}$; Amsbio) for $1 \mathrm{~h}$ at $37^{\circ} \mathrm{C}$ and the remaining GAG $(\mathrm{HS}+\mathrm{CS})$ were quantified according to the DMMB protocol using a $\mathrm{KS}$ calibration curve. The amount of KS was calculated as the difference between the amount of total GAG and the amount of the remaining GAG (HS and CS) quantified in a given sample. The values given per sample are the mean of the values obtained with both strategies.

\section{Structure of HS and CS determined by HPLC}

The overall sulfation pattern of HS and CS disaccharides was determined by HPLC as previously described [11]. Briefly for CS analysis, CS disaccharides were obtained by sample digestion with chondroitinase ABC $(300 \mathrm{mU} /$ $\mathrm{mL}$, Sigma-Aldrich) for $1 \mathrm{~h}$ and $30 \mathrm{~min}$ at $37^{\circ} \mathrm{C}$. For $\mathrm{HS}$ analysis, due to a high amount of CS in the samples, a double digestion of the total GAG extracts was performed with digestion with chondroitinase ABC (300 $\mathrm{mU} / \mathrm{mL}$, Sigma-Aldrich) for $1 \mathrm{~h}$ and $30 \mathrm{~min}$ at $37^{\circ} \mathrm{C}$ and then incubation with a mix of Heparitinases I, II, and III (Iduron, $0.25 \mathrm{mU}$ for each) overnight at $37^{\circ} \mathrm{C}$. The $\mathrm{HS}$ disaccharide composition was determined by subtracting the signal of CS peaks previously obtained from (HS+ $\mathrm{CS})$ peaks. Digested samples (CS and $\mathrm{HS}+\mathrm{CS}$ disaccharides) were filtered, loaded onto a HPLC Proteomix SAX-NP5 column, and eluted with a solvent gradient as previously described [11]. Results are expressed as a percentage of the area of each peak relative to the sum area of all peaks for each sample. 


\section{Heparin/glycosaminoglycan ELISA competition assay to determine GAG capacity to bind HBP}

The capacity of GAG to bind HBP (rh Basic FGF2, rh VEGF-165 (PROMOKINE)) was assessed by an ELISAbased competition assay as previously described [17]. Briefly, 96-well ELISA plates were coated with heparinBSA conjugates, washed, and saturated with 1X PBS, 3\% BSA. Then, HBP were added to each well (FGF2 at 2.5 ng/well; VEGF-165 at $5 \mathrm{ng} /$ well) together with increasing concentrations of GAG extracted from the samples (serial dilutions from 0.01 to $10 \mu \mathrm{g} / \mathrm{mL}$ in PBS) in duplicate. Competition for HBP binding between immobilized heparin and soluble GAG was performed for $1 \mathrm{~h}$ in the plate. After washing, HBP bound to heparin coated onto the plate were incubated with a specific antibody (antiFGF2 Mouse Monoclonal IgG diluted 1/2000, R\&D systems MAB233; anti-VEGF Rabbit Polyclonal IgG, diluted 1/500 PROMOKINE PK-AB815-64420) for $1 \mathrm{~h}$ at RT and then with a HRP-conjugated secondary antibody (HRP-AffiniPure Donkey Anti-Mouse IgG diluted 1/ 5000, Jackson ImmunoResearch 715-035-151; HRPAffiniPure Goat Anti-Rabbit IgG, diluted 1/2000; Jackson ImmunoResearch 111-035-144). The peroxidase activity was measured by oxidation of the $3,3^{\prime}, 5,5^{\prime}$ tetramethylbenzidine (TMB, Thermo Scientific) substrate. The maximum binding (100\%) was determined in the presence of $\mathrm{HBP}$ and in the absence of extracted GAG. The $\mathrm{IC}_{50}$ was defined as the GAG concentration $(\mu \mathrm{g} / \mathrm{mL})$ inhibiting $50 \%$ of HPB binding to immobilized heparin. The $\mathrm{IC}_{50}$ was used to calculate relative binding affinities.

\section{Murine primary chondrocyte cultures and RQ-PCR analysis}

Murine articular chondrocytes were taken from 6-dayold mice as described before [18], and then seeded into plates for proliferation. At day 6, primary chondrocytes were incubated without and with $2.5 \mu \mathrm{g} / \mathrm{mL}$ of GAG extracted from cartilages or with recombinant mouse interleukin-1 $\beta$ (IL-1 $\beta, R \& D$ systems, $1 \mathrm{ng} / \mathrm{mL}$ ) for $24 \mathrm{~h}$. Then, the chondrocyte RNA was recovered using Qiazol reagent (QIAGEN). Reverse transcription was performed using the high capacity cDNA reverse transcription Kit (Applied Biosystems). Real-time PCR was performed using SYBR Green Master Mix (Applied Biosystems) to analyze the pattern of mRNA expression of anabolic (COL2, ACAN, SOX9), catabolic (MMP-3 and 13, ADAMTS 4 and 5), and hypertrophic (VEGF) markers, using previously validated primer sequences [19]. Averaged threshold cycle $(\mathrm{Ct})$ values were normalized to the averaged $\mathrm{Ct}$ value of the housekeeping gene, HPRT1. Adjusted average Ct values were used to calculate the expression level of each gene relative to HPRT1 expression level.

\section{Statistical analysis}

Each GAG sample was tested in duplicate in 3 independent experiments. The mean of the duplicate was the value of the GAG sample reported for one experiment. Statistical analyzes were performed using Graph Pad Prism 5 software. The statistical significance of differences between groups was determined using an ordinary one-way ANOVA and pairwise comparisons were made using a two-tailed unpaired Student's $t$ test or Dunnett's multiple comparison test. Data are expressed as the mean \pm SEM. A significant $P$ value was defined as follows: $*<0.05 ; * * 0.01, * *<0.001, * * * * 0.0001$.

\section{Results}

\section{Donors}

There were 11 OA donors (6 women with a median age of 78 years and 5 men with a median age of 74 years) and 7 control donors ( 6 women with a median age of 82 years and 1 man aged 88 years). The mean KellgrenLawrence score was $1.6 \pm 0.5$ in the control group and $4 \pm 0$ in the OA group.

\section{Sulfated GAG levels are decreased in OA cartilages}

The level of total sulfated GAG (Fig. 1a) was significantly lower in OA cartilages $(15.6 \pm 1.6 \mu \mathrm{g} / \mathrm{mg})$ compared to control cartilages $(25 \pm 2.4 \mu \mathrm{g} / \mathrm{mg})$. Lower CS levels (Fig. 1b) were observed in OA samples $(8.5 \pm 0.5 \mu \mathrm{g} / \mathrm{mg})$ compared to control samples $(9.5 \pm 0.9 \mu \mathrm{g} / \mathrm{mg})$, without reaching significance. However, significantly lower KS (Fig. 1d) and HS (Fig. 1c) levels were measured in OA samples $(4.3 \pm 0.5 \mu \mathrm{g} / \mathrm{mg}$ for $\mathrm{KS}$ and $2.3 \pm 0.3 \mu \mathrm{g} / \mathrm{mg}$ for HS) compared to control samples $(10.5 \pm 1.4 \mu \mathrm{g} / \mathrm{mg}$ for $\mathrm{KS}$ and $4.8 \pm 0.3 \mu \mathrm{g} / \mathrm{mg}$ for HS). Based on these overall differences between control and OA samples, the analysis of the percentage of each GAG species relative to the total amount (Panel E) showed that the CS fraction was increased and the most represented in OA cartilages compared to control ones (respectively 56\% and 38\%). Conversely, the HS and KS fractions were decreased in OA samples compared to control samples (respectively, $20 \%$ and $42 \%$ of total GAG in control samples versus $14 \%$ and $29 \%$ in OA samples).

\section{Sulfated forms of CS and HS disaccharides are increased in $\mathrm{OA}$ cartilages}

The HPLC analysis showed that CS disaccharides (Fig. 2a-c) were mainly monosulfated in control cartilages $(85 \pm 1.2 \%$ ) (Fig. $2 \mathrm{~b}$ ) and that the level of monosulfated CS disaccharides was significantly increased in OA cartilages $(89 \pm 0.1 \%)$. Conversely, the lower fractions of non-sulfated (Fig. 2a) and disulfated (Fig. 2c) CS disaccharides were decreased in OA cartilages $(9.2 \pm 0.2 \%$ and $0.9 \pm 0.06 \%$, respectively) compared to control samples $(13 \pm 0.6 \%$ and $1.1 \pm 0.09 \%$, respectively). HS 

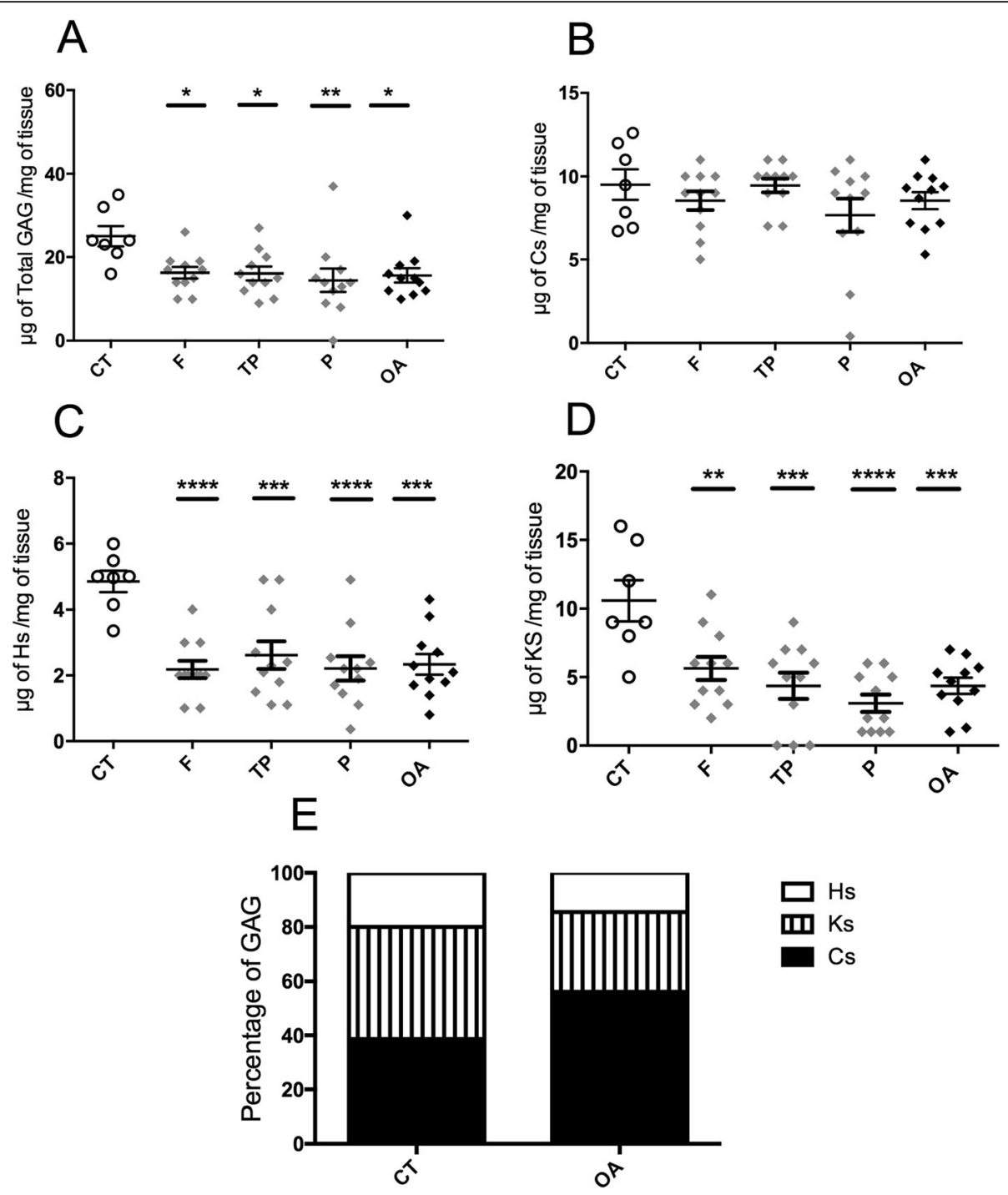

Fig. 1 Quantification of sulfated GAG. The amounts of total sulfated GAG (a) and isolated CS (b), HS (c), and KS (d) were normalized in $\mu \mathrm{g}$ of GAG per mg of articular cartilage from healthy control donors $(C T, n=7)$ and osteoarthritis patients $(O A, n=11)$. The values of the $C T$ group were compared to the values obtained for the femur (F), tibial plateau (TP), and patella (P) samples from OA patients and to the mean of the 3 samples from each OA patient (OA). The value of a GAG sample was the mean of 3 values obtained from 3 independent experiments. All values per group are expressed as a mean \pm SEM. $P$ values were calculated using an ordinary one-way ANOVA test followed by pairwise comparisons using the Dunnett test: ${ }^{*}<0.05,{ }^{* *}<0.01,{ }^{* * *}<0.001,{ }^{* * * *}<0.0001$. e Distribution of HS, KS, and CS amounts as a percentage of the amount of total GAG (100\%)

disaccharides (Fig. 2d-f) were mainly monosulfated in control cartilages $(67 \pm 2.5 \%)$ (Fig. 2e) and the level of monosulfated HS disaccharides was significantly increased in OA cartilages $(84.3 \pm 1.2 \%)$. This was associated with a 3 times lower non-sulfated HS disaccharide level in OA cartilages $(12 \pm 1.1 \%)$ compared to control cartilages $(30 \pm 2.3 \%)$ (Fig. $2 \mathrm{~d}$ ).

\section{Changes in the binding affinity of GAG for growth factors in $O A$ cartilages}

An ELISA-based competition binding assay (Fig. 3 and Table 2) was used to investigate whether the structural changes in GAG from OA cartilages were associated with a different capacity to bind to HBP that are essential for cartilage homeostasis such as FGF2 and VEGF [20, 21]. Total GAG isolated from control cartilages bound to FGF2 (panel A) and inhibited by $50 \%$ its binding to heparin with an $\mathrm{IC}_{50}$ of $11 \pm 4 \mu \mathrm{g} / \mathrm{mL}$ (Table 2). The value obtained with total GAG from control cartilages was defined as a relative binding affinity of $100 \%$ (Fig. 3a). The $\mathrm{IC}_{50}$ of total GAG isolated from OA samples $(84 \pm 20 \mu \mathrm{g} / \mathrm{mL})$ was 8 times higher (Table 2), corresponding to an 8-fold reduction in the binding affinity of GAG from OA 

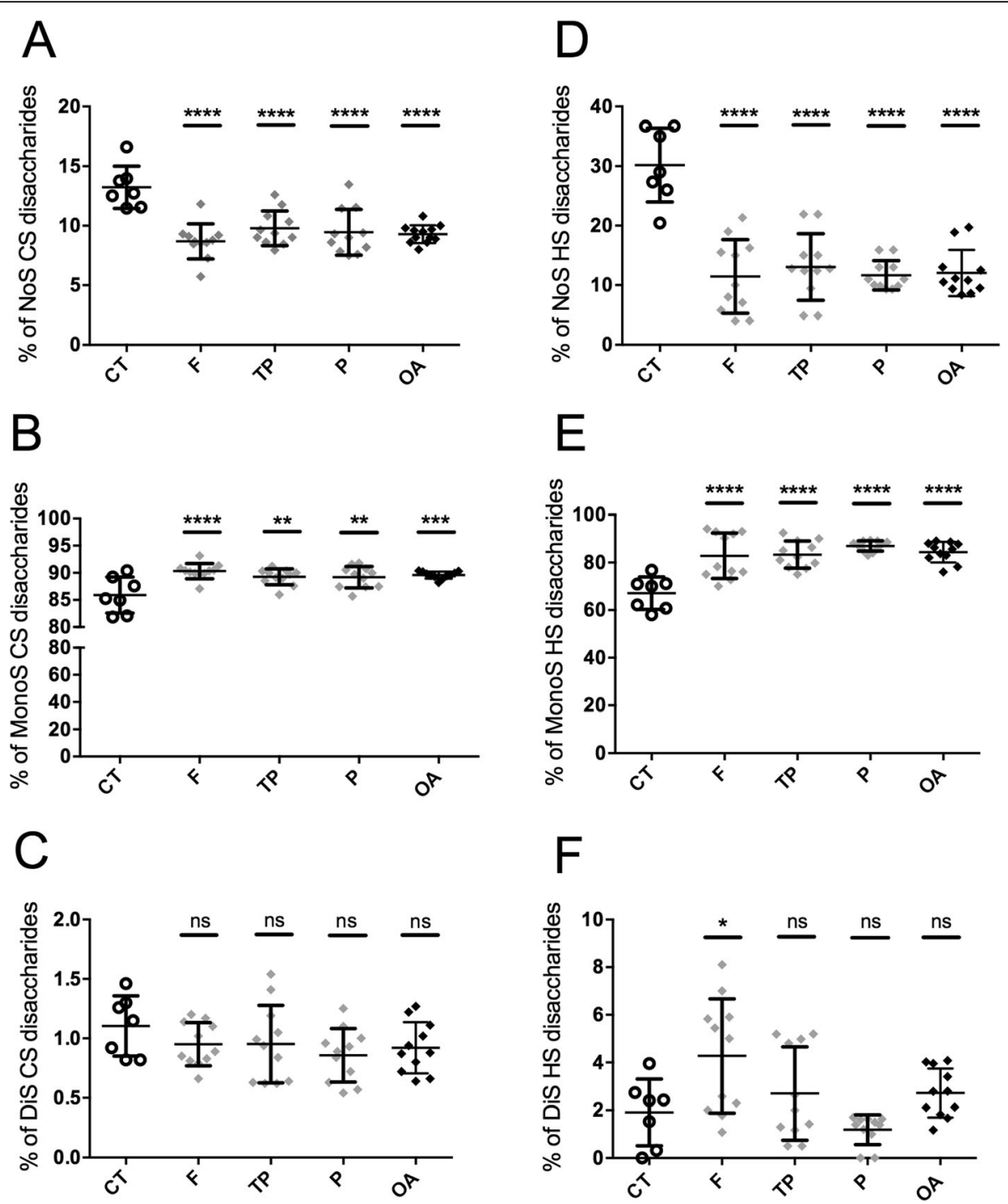

Fig. 2 HPLC analysis of the sulfation pattern of GAG disaccharides. A HPLC analysis was performed on the CS (a-c) and HS (d-f) disaccharide units contained in the GAG chains isolated from cartilages of CT donors $(n=7)$ and OA patients $(n=11)$, to determine the relative composition of each disaccharide unit: non-sulfated (NoS) (a, d), monosulfated (MonoS) (b, e), and disulfated (DiS) (c, f). Each sample was analyzed twice independently. The value of a GAG sample was the mean of 3 values obtained from 3 independent experiments. All values per group are expressed as a mean \pm SEM. The values of the CT group were compared to the value obtained for the different parts of OA cartilages, i.e., the femur (F), tibial plateau (TP), and patella (P), and to the mean of the 3 parts from each OA patient (OA). $P$ values were calculated using an ordinary one-way ANOVA test followed by pairwise comparisons using the Dunnett test: ${ }^{*}<0.05,{ }^{* *}<0.01,{ }^{* * *}<0.001,{ }^{* * *}<0.0001$

samples for FGF2 (12.5 $\pm 0.9 \%)$ compared to control cartilages (100\%) (Fig. 3a). Total GAG from control cartilages did not bind to VEGF (panel B) and did not compete with heparin even at a concentration of $1000 \mu \mathrm{g} / \mathrm{mL}$. Thus, this $\mathrm{IC}_{50}$ was defined as a relative low binding affinity of $1 \%$. Conversely, total GAG isolated from $\mathrm{OA}$ samples bound to VEGF with an $\mathrm{IC}_{50}$ of $136 \pm 78 \mu \mathrm{g} / \mathrm{mL}$ (Table 2), showing a significantly higher binding affinity of total GAG from OA samples for VEGF $(11.6 \pm 1.9 \%)$ compared to total GAG from control samples $(1 \pm 0.1 \%)$ (Fig. $3 b)$.
HS, CS, and KS cooperate in the cartilage to regulate their binding affinity for growth factors

An ELISA-based competition binding assay was performed with CS/KS (a mix of total GAG devoid of HS) from control and OA cartilages and showed that these GAG were not able to compete with immobilized heparin to bind to FGF2 and VEGF (Table 2). Conversely, HS isolated from control cartilages bound to FGF2 and VEGF with an $\mathrm{IC}_{50}$ of $36 \pm 14 \mu \mathrm{g} / \mathrm{mL}$ and $13 \pm 2 \mu \mathrm{g} / \mathrm{mL}$, respectively. These values corresponded to a binding affinity of HS for FGF2 and VEGF of $38.1 \pm 5.5 \%$ and 

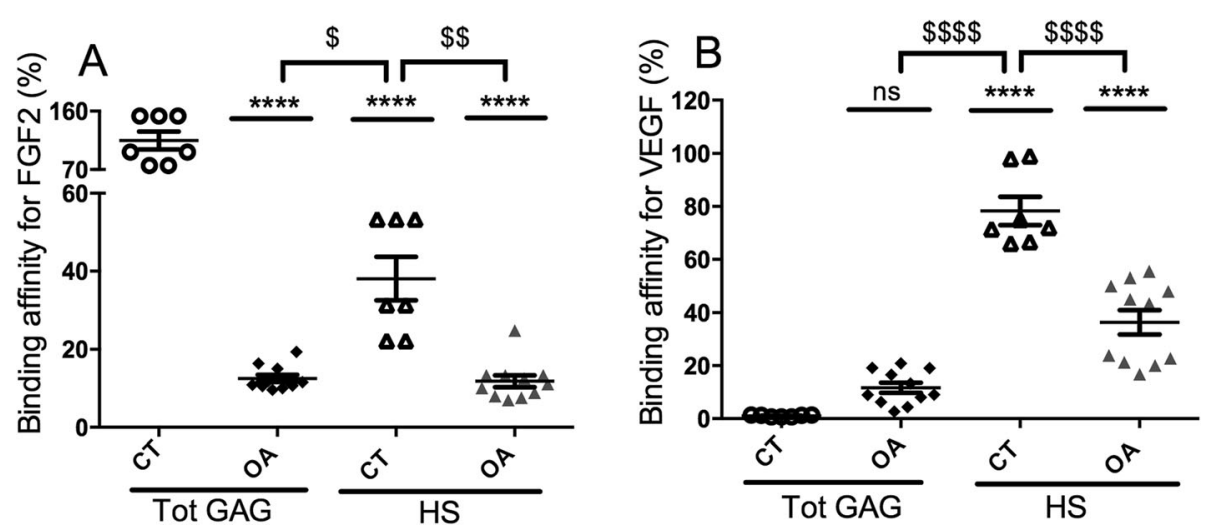

Fig. 3 Percentage of binding affinity of total GAG and HS for FGF2 and VEGF. a The IC 50 of total GAG from control articular cartilages (CT, $n=7$ ) was considered $100 \%$ of binding to FGF2 and used to calculate the \% of binding affinity of all other GAG (OA total GAG, $n=11, \mathrm{CT}$ HS and OA HS) for FGF2. $\mathbf{b}$ The IC $\mathrm{C}_{50}$ of total GAG from control articular cartilages was considered 1\% of binding to VEGF and used to calculate the $\%$ of binding affinity of all other GAG (OA total GAG, $n=11, \mathrm{CT}$ HS and OA HS) for VEGF. Each GAG sample was tested in duplicate in each experiment and the mean of the duplicate was considered the value of the GAG sample. All values per group are expressed as a mean \pm SEM. $P$ values were calculated using an ordinary one-way ANOVA test followed by pairwise comparisons using the Dunnett test compared to CT total GAG (***0.01, $\left.{ }^{* * *}<0.001,{ }^{* * * *}<0.0001\right)$ or to CT HS $\left({ }^{\$}<0.05,{ }^{\$ \$}<0.01,{ }^{\$ \$ \$}<0.001,{ }^{\$ \$ \$}<0.0001\right)$

$78.3 \pm 5.3 \%$, respectively, compared to the reference values of total GAG from control cartilages (Fig. 3a and b). In OA samples, the binding affinities of HS for FGF2 $(11.8 \pm 1.4 \%)$ and VEGF $(36.3 \pm 4.5 \%)$ were significantly decreased by 3 - and 2-folds, respectively, compared to HS control samples (Fig. $3 \mathrm{a}$ and $\mathrm{b}$ ), suggesting that structural changes in HS in OA samples could reduce their affinity for these 2 HBP. Interestingly, the binding affinity for FGF2 in control cartilages was 3 times higher with total GAG (Fig. 3a) $(114.7 \pm 13.6 \%)$ than with isolated HS (38.1 $\pm 5.5 \%)$. This suggested that CS/KS present in total GAG extracts could positively modulate the binding affinity of HS for FGF2. In OA cartilages, total GAG and isolated HS showed similar affinities for
FGF2 $(12.5 \pm 0.9 \%$ and $11.8 \pm 1.4 \%$, respectively), suggesting that $\mathrm{CS} / \mathrm{KS}$ present in total GAG extracts were no longer able to increase HS binding affinity for FGF2 in OA cartilages. Regarding VEGF in control cartilages, the binding affinity of HS was significantly higher than that of total GAG $(78.3 \pm 5.3 \%$ and $1 \pm 0.1 \%$, respectively), suggesting that $C S / K S$ present in total GAG extracts negatively modulate HS binding affinity for VEGF. In OA samples, the binding affinity of HS for VEGF was only twice as high as that of total GAG $(36 \pm 4.5 \%$ and $11.6 \pm 1.9 \%$, respectively), confirming that in the OA context, CS/KS present in total GAG extracts were no longer able to modulate HS binding to VEGF as efficiently as in the control context.

Table $2 I_{50}$ of total GAG, HS, and the mix of CS and KS for FGF2 and VEGF. IC ${ }_{50}$ were determined in $\mu \mathrm{g} / \mathrm{mL}$ and defined as the concentration of tested cartilage GAG able to compete with heparin for $50 \%$ of the binding to HBP (FGF2 and VEGF), and used to calculate the \% of binding affinity shown in Fig. 3

\begin{tabular}{|c|c|c|c|c|c|}
\hline IC50 $(\mu \mathrm{g} / \mathrm{ml})$ & $\mathrm{CT}$ & Femur & Tibial Plateau & Patella & $O A$ \\
\hline \multicolumn{6}{|l|}{ Total GAG } \\
\hline FGF-2 & $11 \pm 4$ & $88 \pm 23$ & $75 \pm 23$ & $91 \pm 1$ & $84 \pm 20$ \\
\hline VEGF & $\mathrm{NoC}$ & $113 \pm 76$ & $187 \pm 125$ & $106 \pm 36$ & $136 \pm 78$ \\
\hline \multicolumn{6}{|l|}{ HS } \\
\hline FGF-2 & $34 \pm 14$ & $74 \pm 31$ & $88 \pm 8$ & $110 \pm 30$ & $82 \pm 25$ \\
\hline VEGF & $13 \pm 2$ & $39 \pm 19$ & $45 \pm 3$ & $21 \pm 2$ & $38 \pm 12$ \\
\hline \multicolumn{6}{|l|}{$C S+K S$} \\
\hline FGF-2 & $\mathrm{NoC}$ & $\mathrm{NoC}$ & $\mathrm{NoC}$ & $\mathrm{NoC}$ & $\mathrm{NoC}$ \\
\hline VEGF & $\mathrm{NoC}$ & $\mathrm{NoC}$ & $\mathrm{NoC}$ & $\mathrm{NoC}$ & $\mathrm{NoC}$ \\
\hline
\end{tabular}

Values correspond to the mean \pm SEM for the CT group $(n=7)$ compared to the different parts of OA cartilages: femur (F), tibial plateau (TP), and patella (P) and to all OA cartilage parts (OA, $n=11)$. Each GAG sample was analyzed in duplicate in three independent experiments. NoC no competition, $H S$ heparan sulfate, $K S$ keratan sulfate, CS chondroitin sulfate 
GAG from OA cartilages induce a catabolic phenotype in murine articular chondrocytes

We investigated whether GAG extracted from OA and control cartilages could affect the anabolic and catabolic phenotypes of murine neonatal articular chondrocytes (Fig. 4). IL-1 $\beta$, used as a positive control, significantly increased the mRNA expression levels of catabolic markers such as MMP3 (814 \pm 11$)$, MMP13 (87 \pm 0.4$)$, ADAMTS4 (1.45 \pm 0.04$)$, ADAMTS5 $(2 \pm 0.1)$, and hypertrophic markers such as VEGF $(4 \pm 0.3)$ compared to cells alone. Cells incubated with GAG from control cartilages showed a slight but significant increase in the mRNA levels of TS4 $(1.4 \pm 0.08)$, SOX9 (1.2 \pm 0.05$)$, and VEGF $(1.7 \pm 0.26)$ compared to cells alone. However, cells incubated with GAG from OA cartilages showed significantly increased mRNA levels of all catabolic markers (MMP3 $945 \pm 74$, MMP13 $68 \pm 7.9$, TS4 $1.8 \pm$ 0.09 , TS5 $2.5 \pm 0.09$ ) and a hypertrophic marker (VEGF $2.8 \pm 0.17)$ associated with decreased mRNA levels of anabolic markers (COL2 $0.6 \pm 0.12$ and SOX9 $0.3 \pm 0.03$ ) compared to cells alone. These findings suggested that GAG from cartilages, especially those from OA patients, could inhibit the expression of anabolic markers and induce a catabolic signaling pathway in chondrocytes in vitro.

\section{Catabolic effects of GAG from OA cartilages are related to their HS species}

The gene expression induced by HS, CS, and KS species isolated from cartilages was assessed in primary chondrocyte cultures (Fig. 5). HS from control cartilages significantly increased the mRNA levels of MMP3 (15.6 \pm $1.2)$ and MMP13 $(5.7 \pm 0.4)$ and significantly decreased the mRNA levels of COL2 $(0.6 \pm 0.01)$ compared to cells alone. HS from OA cartilages showed significantly stronger modulatory effects on 7 out of the 8 markers tested compared to cells alone. Indeed, strong increases in the mRNA levels of MMP3 (43.1 \pm 4.2$)$, MMP13 (3.3 \pm 0.1$)$, and TS4 $(1.3 \pm 0.05)$ and decreases in the mRNA levels of COL2 $(0.5 \pm 0.02)$, ACAN $(0.5 \pm 0.01)$, SOX9 $(0.2 \pm$ $0.01)$, and VEGF $(0.4 \pm 0.03)$ were observed. These findings suggested that cartilaginous HS had catabolic effects that were strongly enhanced in OA samples. Indeed, the difference between HS from control and OA cartilages (\$) was significant for 6 out of the 8 markers tested: MMP3, MMP13, COL2, ACAN, SOX9, and VEGF. CS from control cartilages significantly increased the mRNA levels of MMP3 $(9.1 \pm 0.5)$ and MMP13 $(3.8 \pm 0.5)$ and decreased the mRNA levels of COL2 $(0.6 \pm 0.01)$ and SOX9 $(0.4 \pm 0.01)$ compared to cells alone. CS from OA cartilages significantly increased the mRNA levels of MMP3 $(6.3 \pm 0.5)$ and MMP13 $(6.5 \pm 0.7)$ and decreased the mRNA levels of SOX9 $(0.5 \pm 0.006)$ and VEGF $(0.5 \pm$ $0.01)$ compared to cells alone. These findings suggested that control cartilaginous CS had catabolic effects on chondrocytes that were maintained in OA samples. Similarly, KS from control cartilages induced a significant increase in the mRNA levels of MMP3 (22.3 \pm 3.5$)$, MMP13 (3.3 \pm 0.4$)$, and TS4 (1.45 \pm 0.04 DDCT) and a decrease in the mRNA levels of COL2 $(0.86 \pm 0.01)$ and SOX9 $(0.56 \pm 0.04)$ compared to cells alone, suggesting that they could also have a catabolic effect. The same catabolic effect was observed with KS from OA cartilages, with a significant increase in the mRNA levels of MMP3 $(12 \pm 1.3)$ and TS4 $(1.49 \pm 0.03)$ and a decrease in the mRNA levels of COL2 $(0.76 \pm 0.01)$ compared to cells alone. The difference between $\mathrm{KS}$ from control and OA samples was highly significant for the mRNA levels of COL2 and SOX9. CS and KS from OA samples were no longer able to inhibit the mRNA levels of these two anabolic markers. These findings suggested that CS, KS, and HS were individually able to disrupt the balance between anabolism and catabolism in chondrocytes but that the HS species had the strongest effect.

\section{Discussion}

The role of HSPG in OA has been barely investigated, in particular changes in their functional capacities according to the degree of sulfation of HS chains. Our GAG extraction protocol allowed isolating sufficient amounts of HS from cartilages for studying their structure and functional effects, including their binding affinity for HBP. We found a 2-fold decrease in HS levels in OA cartilages compared to controls, in accordance with previous works that have shown a lower decrease in $\mathrm{HS}$ probably due to a lower yield of HS extraction [7]. Changes also affected the composition of other GAG.

We showed that the levels of monosulfated CS disaccharides were increased in OA cartilages. This finding is in line with a report showing an increase in monosulfated CS levels (GalNAc 6-O-sulfation) in $\mathrm{OA}$ and changes in the CS4/CS6 ratio [22]. This could be related to changes in aggrecan composition, which in turn could influence chondrocyte metabolism and properties, resulting in $\mathrm{OA}$ but the underlying mechanisms are still poorly understood [23]. Monosulfated disaccharides were the main HS forms observed in human control cartilages, and this fraction was increased in OA, together with the appearance of disulfated disaccharides. This could be due to the presence of neosynthesized HS with $\mathrm{N}$-sulfation, due to the activity of the sulfotransferase Ndst which determines high sulfation regions in the HS chain. Parra et al. have shown a very high degree of sulfation, similar to that of heparin, of minor HS present in growth plates and mature articular cartilages in young rabbits using a NMR structural analysis [21, 22]. Such highly sulfated HS could be produced as a functional response to the need of a growing tissue with strong 

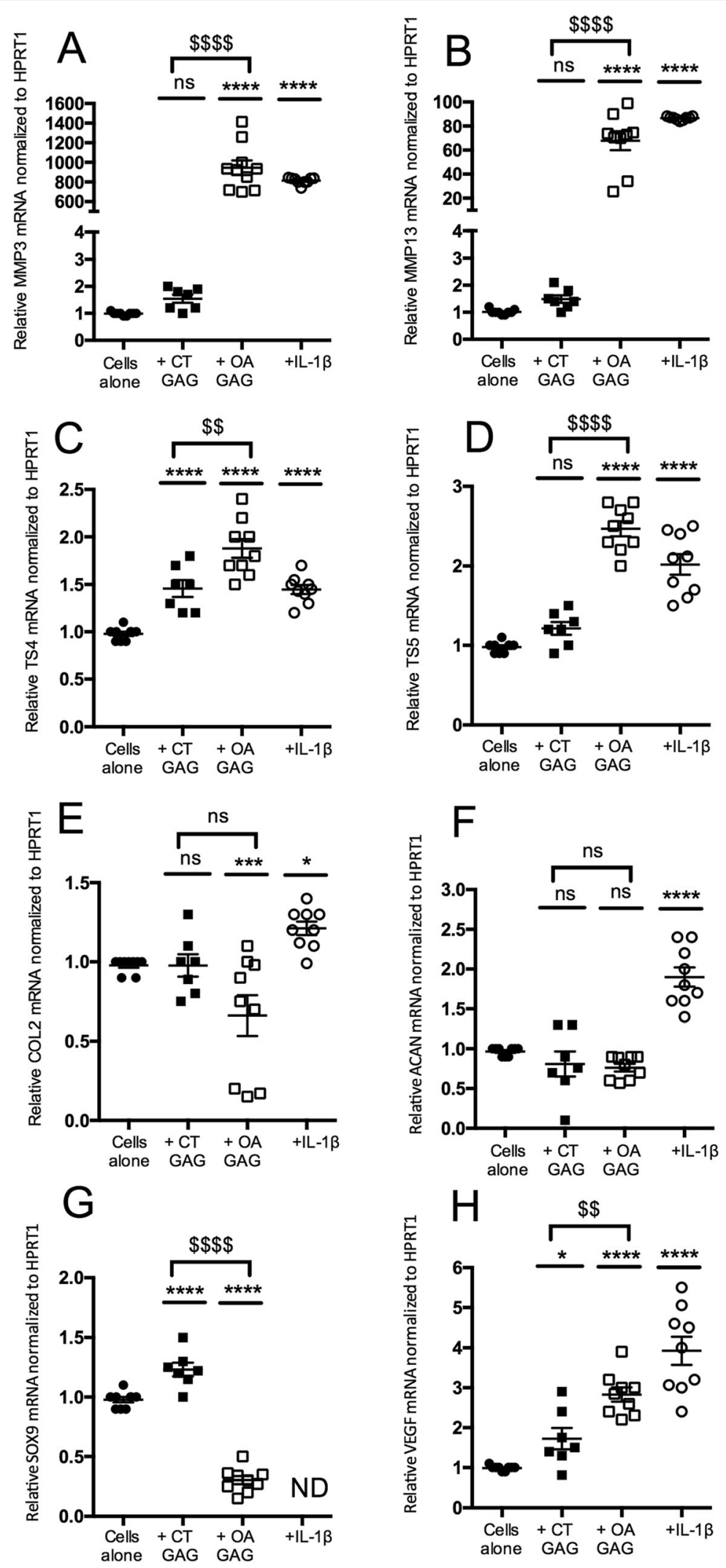

Fig. 4 (See legend on next page.) 
(See figure on previous page.)

Fig. 4 Effect of GAG from cartilages on murine chondrocyte phenotypes. Articular chondrocytes were grown in the absence (cells alone) or in the presence of total GAG $(2.5 \mu \mathrm{g} / \mathrm{mL})$ from the cartilage of control donors (CT GAG) or osteoarthritis patients (OA GAG), or in the presence of IL$1 \beta(1 \mathrm{ng} / \mathrm{mL})$. RQ-PCR analysis of the mRNA expression levels of catabolic markers, MMP3 (a), MMP13 (b), TS4 (c), and TS5 (d); anabolic markers, COL2 $(\mathbf{e})$, ACAN (f) and SOX9 (g); and a hypertrophic marker, VEGF (h), reported to HPRT1 expression level (housekeeping gene) and compared to the basal condition (cells alone) defined as 1 (100\%). Data is presented as the mean of 9 values obtained from 3 independent experiments in CT ( $n=3$ samples) and OA ( $n=3$ samples) cartilages. The statistical significance of the differences was determined using an ordinary one-way ANOVA test followed by pairwise comparisons using the Dunnett test compared to cells alone $\left(^{*}\right)$ and by a $t$ test between CT GAG and OA GAG (\$). Significant $P$ values: ${ }^{*}<0.05,{ }^{* *}<0.01,{ }^{* *}<0.001,{ }^{* * * *}<0.0001,{ }^{\$ \$}<0.01$, and ${ }^{\$ \$ \$}<0.0001$

chondrocyte proliferation. Accordingly, Chanalaris et al. have shown a significant increase in 6-O-sulfation in HS disaccharides from human OA samples compared to controls [7]. Thus, it could be assumed that the sulfation pattern of HS could vary according to species, age, cartilage type, and cell metabolism.

Compared to other published studies assessing changes in HS levels and sulfation pattern in OA, the main original result of our work is that we observed changes in the binding affinities of HS, CS, and KS isolated from OA samples for $\mathrm{HBP}$ and a change in the balance between anabolism and catabolism in chondrocytes.

It is likely that, in the in vitro cell system used, the plated chondrocytes expressed cell surface and pericellular HS proteoglycans that bound to HS ligands present in the culture medium, with a maintained balance between the anabolic and catabolic activities. Thus, the increased catabolic effects observed when adding HS from OA cartilages could be explained by different biological effects: (i) a direct effect on the binding and activity of catabolic factors present in the culture medium and/or secreted by chondrocytes and that will be strongly induced to interact with their receptors, inducing catabolic phenotypes and (ii) an indirect or competitive effect, since exogenous GAG could displace anabolic growth factors from the cell layer, preventing their interaction with their receptors. Thus, the increased catabolic effects observed in the presence of HS from OA cartilages could be due to a higher affinity for all types (anabolic or catabolic) of growth factors.

Interestingly, we showed that total GAG from control cartilages were able to bind to FGF2, but mainly due to the binding affinity of HS for this HBP, which was decreased in OA cartilages. FGF2 is endogenously produced by chondrocytes and sequestered by perlecan, a matrix HSPG, in the ECM of the articular cartilage [24, $25]$. When the cartilage is damaged, FGF2 is released from perlecan HS chains [26] to subsequently activate the ERK signaling pathway [27]. This has been associated with catabolic effects in human articular chondrocytes via an upregulation of matrix degrading enzymes, the inhibition of ECM accumulation, an increased PG synthesis, and the clustering of cells characteristic of OA [28]. We showed here that altered HS levels and sulfation patterns in human OA cartilages were associated with a decreased binding affinity of HS for FGF2. We hypothesized that this lower binding affinity of HS chains for FGF2 could be associated with a decrease in its sequestration by perlecan in the ECM and thus with an increase in FGF2 bioavailability and catabolic activity on chondrocytes.

We observed increased levels of monosulfated and disulfated disaccharides forms of $\mathrm{HS}$ from OA cartilages that could be due to a first increased level of $\mathrm{N}$-sulfation pattern. Recently, Severmann et al. have analyzed the role of HS levels and sulfation patterns in OA induced in transgenic mice carrying a chondrocytespecific loss-of-function allele of Ext1 and of Ndst1 [29]. Mouse strains with reduced HS levels and sulfated HS showed reduced OA scores, suggesting that "highly" sulfated HS could regulate cartilage degeneration through an effect on the protease activity. FGF2 binds preferentially to HS containing iduronate-2-O-sulfation and glucosamine- $\mathrm{N}$-sulfates, whereas 6 -O-sulfation is essential for the receptor engagement in the trimolecular FGF2/FGFR/HS signaling complex and its mitogenic activity [30-32]. The 6-O-sulfation levels clearly regulate FGF2-induced receptor phosphorylation, FGFR1 internalization, and downstream FGF2-dependent endothelial phenotypes in vitro and in vivo [33].

We showed that while total GAG from control cartilages did not bind to VEGF, total GAG from OA cartilages were able to bind to it and this still mainly due to the binding affinity of HS for this HBP. Interestingly, VEGF expression is increased in OA cartilages and correlates with the severity of the disease. Accordingly, VEGF is a procatabolic and proangiogenic factor in OA that induces MMP13 expression, osteophyte formation, and differentiation towards a hypertrophic state [21]. In animal models of OA, VEGF blockade using monoclonal antibodies or in $\mathrm{KO}$ mice decreased OA severity, while an intra-articular injection of VEGF worsened cartilage damage [26, 27]. Thus, our data suggests that the increased binding affinity of total GAG from OA cartilages for VEGF could play a role in various catabolic processes. 

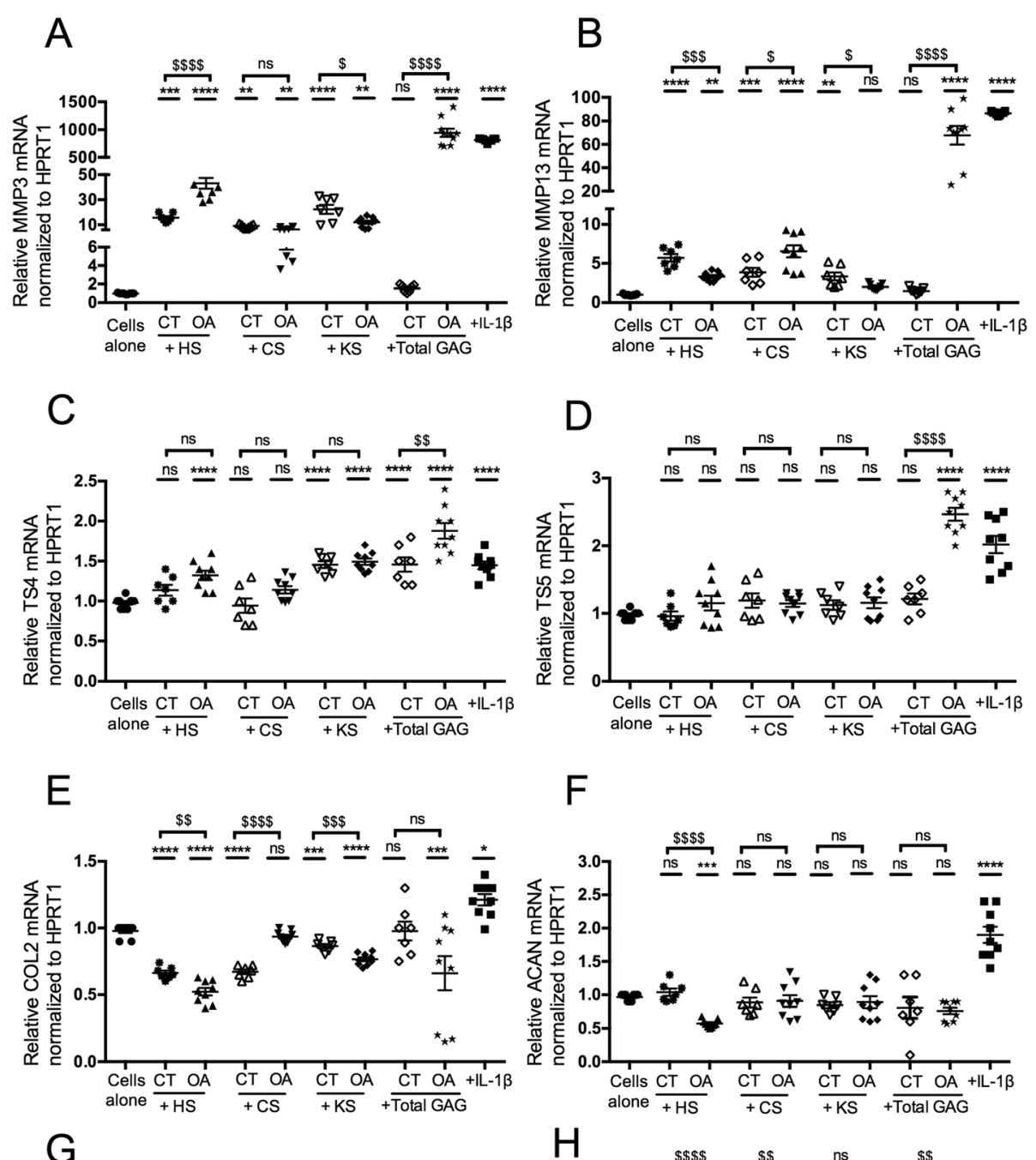

$\mathrm{F}$
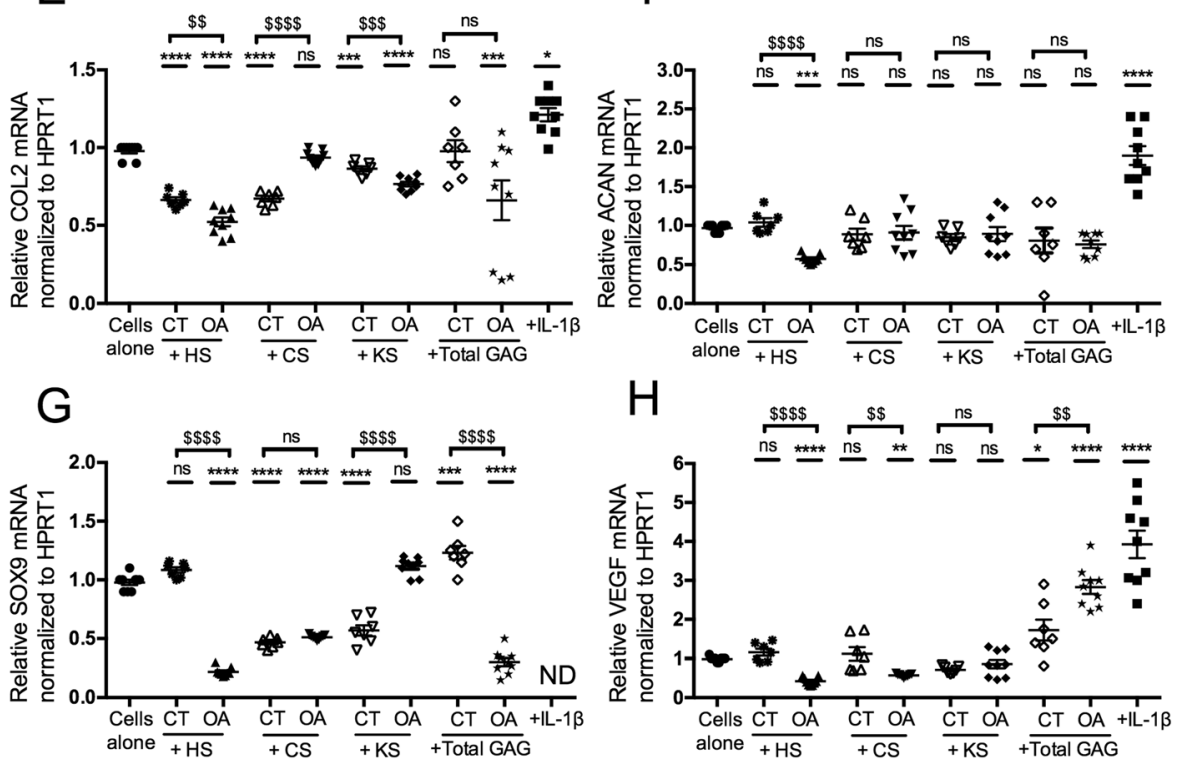

Fig. 5 Effect of HS, CS, and KS isolated from cartilages on murine chondrocyte phenotypes. Articular chondrocytes were grown in the absence (cells alone) or in the presence of $\mathrm{HS}, \mathrm{CS}$, or $\mathrm{KS}(2.5 \mathrm{\mu g} / \mathrm{mL})$ isolated from cartilages of control donors $(\mathrm{CT})$ or osteoarthritis patients $(\mathrm{OA})$, or in the presence of IL-1 $\beta(1 \mathrm{ng} / \mathrm{mL})$. RQ-PCR analysis of the mRNA expression levels of catabolic markers, MMP3 (a), MMP13 (b)), TS4 (c) and TS5 (d); anabolic markers, COL2 (e), ACAN (f), and SOX9 (g); and a hypertrophic marker, VEGF (h), reported to HPRT1 expression level (housekeeping gene) and compared to the basal condition (cells alone) defined as 1 (or 100\%). Data is presented as the mean of 9 values obtained from 3 independent experiments in CT ( $n=3$ samples) and OA ( $n=3$ samples) cartilages. The statistical significance of the differences was determined using an ordinary one-way ANOVA test followed by pairwise comparisons using the Dunnett test compared to cells alone $\left(^{*}\right)$ and by a $t$ test between CT GAG and OA GAG (\$). Significant $P$ values: ${ }^{*}<0.05,{ }^{* *}<0.01,{ }^{* * *}<0.001,{ }^{* * *}<0.0001,{ }^{\$}<0.05,{ }^{\$ \$}<0.01,{ }^{\$ \$ \$}<0.001,{ }^{\$ \$ \$ \$}<0.0001$

Key structural features of highly sulfated HS domains mediate the specific binding of the VEGF-165 dimer to its receptors: the carboxylate groups and 2-O-, 6-O-, and $\mathrm{N}$-sulfation of $\mathrm{HS}$ contribute to the strength of
VEGF-165 interactions. However, N-sulfates and 6-Osulfates appear to be particularly important for VEGF165 binding [34]. While a high content of 2-O-sulfate groups is not required for the specific interaction with 
VEGF-165, it is essential for its mitogenic activity [35]. Moreover, HS structures with reduced 6-O-sulfation negatively affect VEGF-165-dependent endothelial phenotypes in vitro and in vivo, confirming that the 60 -sulfation pattern is important for the biological activity [33].

As described in the literature, $\mathrm{N}$-sulfated $\mathrm{HS}$ and/or sulfated 6-O-HS are increased during OA leading to enhanced binding affinity of HS to FGF2 and VEGF. However, our in vitro binding assay on HS isolated from cartilage indicates that increased sulfation of HS in OA is associated with reduced binding of HS to FGF2 and VEGF. This suggests that much more complicated sulfation patterns of HS chains are involved, a process that is probably timely regulated. Moreover, they could have different modulatory effects on cells depending on the successive interactions with their receptors when CS and KS are present.

In this context, newly produced sulfated HS, as shown by the OA-related generation of disulfated disaccharides, could require changes in the expression pattern of the complex network of enzymes involved in HS biosynthesis such as anabolic glycosyl transferases (EXTs and EXTLs), epimerases and sulfotransferases (NDSTs and HSTSs), as well as catabolic heparanase and HS 6-Oendosulfatases (Sulfs) [36]. Increased 6-O-sulfation levels in OA have recently been correlated with an increased expression of HS6ST1, a 6-O-sulfotransferase, and GLCE, an epimerase promoting 6-O-sulfation, suggesting that changes in 6-O-sulfation could have an impact on a key signaling pathway in the cartilage [7]. Moreover, the endosulfatases, Sulf1 and Sulf2, are overexpressed in human OA tissues $[37,38]$ and spontaneous cartilage degeneration and surgically-induced $\mathrm{OA}$ have been shown to be significantly more severe in Sulf1 $1^{-1-}$ and Sulf2 ${ }^{-/-}$mice compared to wild-type mice [39]. Accordingly, an intra-articular injection of Sulf1 in a mouse model of OA prevented cartilage degeneration [40]. This suggests that 6-O-HS desulfation could have a protective effect in OA. Our results are in accordance with these findings demonstrating the functional relevance of oversulfated HS, with an impaired binding to FGF2 and VEGF and a resulting catabolic phenotype in chondrocytes in OA.

In this work, we focused on developing a protocol for HS isolation, while ensuring efficient digestions with chondroitinase and keratinase. No purification step of the disaccharides was performed because previous data from the literature has shown the efficacy of chondroitinase $A B C$ digestion in reducing the functional activity of various CS preparations. It has been shown that digested CS-E and CS-H are no longer able to bind to heparinbinding growth factors (HBGF) such as FGF2, FGF1, FGF18, or PTN; inhibit the binding of full-length CS to
HBGF; and induce neurite outgrowth of embryonic rat hippocampal neurons [41]. This phenomenon has been shown to be size dependent with CS disaccharides losing all their binding and biological activities [42]. This suggests that CS disaccharides, although they are much more concentrated than HS, will not have any effect on the binding of HS to protein ligands.

Finally, our binding experiments support an important regulatory role of the CS/KS species in the binding properties of GAG extracted from cartilages, reflecting their modulatory effects on HS affinity for FGF2 and VEGF. In control cartilages, HS were able to bind to FGF2, but with total GAG extracts containing a mix of CS and KS, this binding affinity was increased, perhaps to allow a better retention of FGF2 in the matrix. Similarly, HS from control cartilages bound to VEGF with a strong affinity, but the binding of the mix of CS and KS in total GAG extracts was completely suppressed. Although differences observed in an in vitro biochemical binding test are less biologically significant than in vivo findings, our results suggest that $\mathrm{HS}, \mathrm{CS}$, and KS interactions are regulated by a complex interplay that could depend on the HBP involved and on the proteoglycans carrying the GAG chains. Our data revealed that in OA samples, together with the decreased binding affinity of HS for FGF2 and VEGF, the modulatory properties of CS/KS were lost or decreased. The mix of CS and KS was no longer able to increase HS binding to FGF2 and to decrease HS binding to VEGF. This could also be due to complex structural changes in and/or an altered sulfation of CS and KS chains.

Such an assumption should also take into account the real location of HS, CS, and KS chains on PG in the cartilage. While, in the cartilage, HS are mainly located in the pericellular region, most $\mathrm{CS} / \mathrm{KS}$ on aggrecan are located in the inter-territorial zone and are largely excluded from the pericellular region. However, this does not exclude the fact that some pericellular HSPG, such as perlecan or syndecan, could be substituted for CS or KS chains associated with HS chains. Mammalian perlecan is predominantly substituted for HS chains but it may also be substituted for CS, dermatan sulfate (DS), HS/CS hybrid, and CS/DS chains at the main GAG attachment sites on domains I [43, 44] and V [45]. Syndecans were the first hybrid-type PG described to carry both HS and CS chains. Syndecans from different cell types are found as discrete isoforms with variability in the type, number, and size of GAG chains attached, resulting in various potential interactions [46]. The role of HS chains is to attract and present different proteins at the cell surface, whereas the role of CS (and the related DS) chains, that bind to matrix proteins [47] and soluble molecules [48], would be to change the interactions between syndecans, their HS chains, and other 
proteins, as shown for midkine and pleiotrophin [49, 50]. We could therefore propose a molecular mechanism in which the CS/KS chains viscinity with HS chains on the same core protein and the associated polyvalent chain arrangement will affect and stabilize the direct interactions between HS chains and HBP, even if here, the CS and KS chains from cartilages did not directly interact with the tested HBP. Our results suggest a new role of CS and KS that could regulate the availability of HS functional chains for their target HBP. The complex interactions between the various sulfation patterns of the mix of HS, CS, and KS remain to be elucidated.

\section{Conclusions}

In this study, we showed that GAG from human OA cartilages were able to change the catabolic/anabolic balance of normal chondrocytes and, more surprisingly, that this effect was mainly due to HS functional properties in a cartilage matrix enriched in CS and KS. It remains to be clarified whether a particular PG core protein is carrying the deleterious HS chains or if these chains are present in all HSPG expressed in OA articular cartilages, and how the mix of HS, KS, and CS interplay to promote OA during aging.

\section{Abbreviations \\ ADAMTS: Disintegrin and metalloproteinase with thrombospondin; CDNA: Complementary DNA; COL2: Type 2 collagen; CS: Chondroitin sulfate; CT: Control; DMMB: Dimethyl-methylene blue; ECM: Extracellular matrix; ELISA: Enzyme-linked immunosorbent assay; ERK: Extracellular signal- regulated kinase; EXTLs: Exostosin-like; EXTs: Exostosin; F: Femur; FGF: Fibroblast growth factor; GAG: Glycosaminoglycans; GalNAc: N- Acetylgalactosamine; GLCE: Glucuronyl C5-epimerase; HA: Hyaluronic acid; HBP: Heparin-binding protein; HPLC: High-performance liquid chromatography; HPRT: Hypoxanthine-guanine phosphoribosyltransferase; HS: Heparan sulfate; HSPG: Heparan sulfate proteoglycans; HSTS: Heparan sulfate sulfotransferases; $I_{50}$ : Half maximal inhibitory concentration; IL- 1ß: Interleukin-1 beta; KO: Knockout; KS: Keratin sulfate; MMP: Matrix metalloproteinases; NDST: N-deacetylase/N-sulfotransferases; NMR: Nuclear magnetic resonance; OA: Osteoarthritis; P: Patella; PG: Proteoglycan; RNA: Ribonucleic acid; RQ-PCR: Quantitative polymerase chain reaction; SOX9: Transcription factor SOX-9; TP: Tibia plateau; VEGF: Vascular endothelial growth factor}

\section{Acknowledgements}

The authors would like to thank Fondation Arthritis, Société Francaise de Rhumatology (SFR), and Agence Nationale de la Recherche (ANR) for funding this work.

\section{Authors' contributions}

$\mathrm{SSH}$, designed and performed the experiments, acquired and analyzed the data, and wrote the manuscript. SCH, CF, NHCH, YJ, and EH performed the experiments and acquired and analyzed the data. MCS, DPG, and FE revised the manuscript. XCH designed the experiments, analyzed the data, and revised and edited the manuscript. PA conceived and designed the research study, performed the experiments, acquired and analyzed the data, and wrote the manuscript. The authors read and approved the final manuscript.

\section{Funding}

This work was supported by Fondation Arthritis, Société Francaise de Rhumatology (SFR), and Agence Nationale de la Recherche (ANR).
Availability of data and materials

The datasets used and/or analyzed in this study can be provided by the corresponding author on reasonable request.

Ethics approval and consent to participate

Human cartilage explants were obtained following patient informed consent and according to the legal authorization of the Ethics Committee of the Rheumatology Department of Henri Mondor Hospital (no. 07-34).

\section{Consent for publication}

Not applicable.

\section{Competing interests}

The authors declare to have no conflicts of interest.

\section{Author details}

'Univ Paris Est Creteil, Gly-CRRET, Glycobiology Cell Growth Tissue Repair and Regeneration Research Unit, Créteil F-94010, France. ${ }^{2}$ INSERM, UMR-S 1132 Bioscar, Centre Viggo Petersen, Hôpital Lariboisière, 2, Rue Ambroise Paré" Creteil F-94010, France. ${ }^{3}$ BIOSCAR Inserm U1132, Université de Paris, F-75010 Paris, France. ${ }^{4}$ INSERM, UMR-S 1132 Bioscar, Centre Viggo Petersen, Hôpital Lariboisière, 2, Rue Ambroise Paré, Créteil 75010, France. ${ }^{5}$ Université de Paris (UFR de Médecine), Paris 75010, France.

Received: 6 June 2020 Accepted: 12 October 2020

Published online: 07 December 2020

\section{References}

1. Guillemin F, Rat A-C, Roux CH, Fautrel B, Mazieres B, Chevalier X, et al. The KHOALA cohort of knee and hip osteoarthritis in France. Joint Bone Spine. 2012;79(6):597-603.

2. Nazempour A, Van Wie BJ. Chondrocytes, mesenchymal stem cells, and their combination in articular cartilage regenerative medicine. Ann Biomed Eng. 2016;44(5):1325-54.

3. Kirsch T, Swoboda B, Nah H. Activation of annexin II and V expression, terminal differentiation, mineralization and apoptosis in human osteoarthritic cartilage. Osteoarthr Cartil. 2000;8(4):294-302.

4. Hitchcock AM, Yates KE, Costello CE, Zaia J. Comparative glycomics of connective tissue glycosaminoglycans. Proteomics. 2008:8(7):1384-97.

5. Lohmander LS, lonescu M, Jugessur $H$, Poole AR. Changes in joint cartilage aggrecan after knee injury and in osteoarthritis. Arthritis Rheum. 1999:42(3):534-44.

6. Lark MW, Bayne EK, Flanagan J, Harper CF, Hoerrner LA, Hutchinson NI, et al. Aggrecan degradation in human cartilage. Evidence for both matrix metalloproteinase and aggrecanase activity in normal, osteoarthritic, and rheumatoid joints. J Clin Invest. 1997:100(1):93-106.

7. Chanalaris A, Clarke H, Guimond SE, Vincent TL, Turnbull JE, Troeberg L. Heparan sulfate proteoglycan synthesis is dysregulated in human osteoarthritic cartilage. Am J Pathol. 2019;189(3):632-47.

8. Gandhi NS, Mancera RL. The structure of glycosaminoglycans and their interactions with proteins. Chem Biol Drug Des. 2008;72(6):455-82.

9. Friedl A, Chang Z, Tierney A, Rapraeger AC. Differential binding of fibroblast growth factor-2 and -7 to basement membrane heparan sulfate: comparison of normal and abnormal human tissues. Am J Pathol. 1997;150(4):1443-55.

10. Handel TM, Johnson Z, Crown SE, Lau EK, Proudfoot AE. Regulation of protein function by glycosaminoglycans--as exemplified by chemokines. Annu Rev Biochem. 2005:74:385-410

11. Huynh MB, Morin C, Carpentier G, Garcia-Filipe S, Talhas-Perret S, BarbierChassefière $\mathrm{V}$, et al. Age-related changes in rat myocardium involve altered capacities of glycosaminoglycans to potentiate growth factor functions and heparan sulfate-altered sulfation. J Biol Chem. 2012;287(14):11363-73.

12. Huynh MB, Villares J, Díaz JES, Christiaans S, Carpentier G, Ouidja MO, et al. Glycosaminoglycans from aged human hippocampus have altered capacities to regulate trophic factors activities but not A 422 peptide toxicity. Neurobiol Aging. 2012;33(5):1005.e11-22.

13. Sepulveda-Diaz JE, Alavi Naini SM, Huynh MB, Ouidja MO, Yanicostas C, Chantepie S, et al. HS3ST2 expression is critical for the abnormal phosphorylation of tau in Alzheimer's disease-related tau pathology. Brain. 2015;138(Pt 5):1339-54. 
14. Martinaud C, Desterke C, Konopacki J, Pieri L, Torossian F, Golub R, et al. Osteogenic potential of mesenchymal stromal cells contributes to primary myelofibrosis. Cancer Res. 2015;75(22):4753-65.

15. Petersson IF, Boegård T, Saxne T, Silman AJ, Svensson B. Radiographic osteoarthritis of the knee classified by the Ahlbäck and Kellgren \& Lawrence systems for the tibiofemoral joint in people aged 35-54 years with chronic knee pain. Ann Rheum Dis. 1997;56(8):493-6.

16. Barbosa I, Garcia S, Barbier-Chassefière V, Caruelle J-P, Martelly I, Papy-García D. Improved and simple micro assay for sulfated glycosaminoglycans quantification in biological extracts and its use in skin and muscle tissue studies. Glycobiology. 2003;13(9):647-53.

17. Najjam S, Gibbs RV, Gordon MY, Rider CC. Characterization of human recombinant interleukin 2 binding to heparin and heparan sulfate using an ELISA approach. Cytokine. 1997;9(12):1013-22.

18. Gosset M, Berenbaum F, Thirion S, Jacques C. Primary culture and phenotyping of murine chondrocytes. Nat Protoc. 2008;3(8):1253-60.

19. Funck-Brentano T, Bouaziz W, Marty C, Geoffroy V, Hay E, Cohen-Solal M. Dkk-1-mediated inhibition of Wnt signaling in bone ameliorates osteoarthritis in mice. Arthritis Rheumatol. 2014;66(11):3028-39.

20. Li X, Ellman MB, Kroin JS, Chen D, Yan D, Mikecz K, et al. Species-specific biological effects of FGF-2 in articular cartilage: implication for distinct roles within the FGF receptor family. J Cell Biochem. 2012;113(7):2532-42.

21. Murata M, Yudoh K, Masuko K. The potential role of vascular endothelial growth factor (VEGF) in cartilage: how the angiogenic factor could be involved in the pathogenesis of osteoarthritis? Osteoarthr Cartil. 2008;16(3):279-86.

22. Lauder RM, Huckerby TN, Brown GM, Bayliss MT, Nieduszynski IA. Agerelated changes in the sulphation of the chondroitin sulphate linkage region from human articular cartilage aggrecan. Biochem J. 2001; 358(Pt 2):523-8.

23. Dudhia J. Aggrecan, aging and assembly in articular cartilage. Cell Mol Life Sci. 2005;62(19-20):2241-56.

24. Vincent TL, McLean CJ, Full LE, Peston D, Saklatvala J. FGF-2 is bound to perlecan in the pericellular matrix of articular cartilage, where it acts as a chondrocyte mechanotransducer. Osteoarthr Cartil. 2007;15(7):752-63.

25. Handler M, Yurchenco PD, lozzo RV. Developmental expression of perlecan during murine embryogenesis. Dev Dyn. 1997;210(2):130-45.

26. Shu CC, Jackson MT, Smith MM, Smith SM, Penm S, Lord MS, et al. Ablation of perlecan domain 1 heparan sulfate reduces progressive cartilage degradation, synovitis, and osteophyte size in a preclinical model of posttraumatic osteoarthritis. Arthritis Rheumatol. 2016:68(4):868-79.

27. Vincent AM, Feldman EL. Control of cell survival by IGF signaling pathways. Growth Hormon IGF Res. 2002;12(4):193-7.

28. Ellman MB, Yan D, Ahmadinia K, Chen D, An HS, Im HJ. Fibroblast growth factor control of cartilage homeostasis. J Cell Biochem. 2013;114(4):735-42.

29. Severmann A-C, Jochmann K, Feller K, Bachvarova V, Piombo V, Stange R, et al. An altered heparan sulfate structure in the articular cartilage protects against osteoarthritis. Osteoarthr Cartil. 2020;28(7):977-87.

30. Turnbull JE, Fernig DG, Ke Y, Wilkinson MC, Gallagher JT. Identification of the basic fibroblast growth factor binding sequence in fibroblast heparan sulfate. J Biol Chem. 1992;267(15):10337-41.

31. Guimond S, Maccarana M, Olwin BB, Lindahl U, Rapraeger AC. Activating and inhibitory heparin sequences for FGF-2 (basic FGF). Distinct requirements for FGF-1, FGF-2, and FGF-4. J Biol Chem. 1993; 268(32):23906-14

32. Pye DA, Vives RR, Turnbull JE, Hyde P, Gallagher JT. Heparan sulfate oligosaccharides require 6-O-sulfation for promotion of basic fibroblast growth factor mitogenic activity. J Biol Chem. 1998;273(36):22936-42.

33. Ferreras $C$, Rushton $G$, Cole $C L$, Babur M, Telfer BA, van Kuppevelt $T H$, et al. Endothelial heparan sulfate 6-O-sulfation levels regulate angiogenic responses of endothelial cells to fibroblast growth factor 2 and vascular endothelial growth factor. J Biol Chem. 2012;287(43): 36132-46.

34. Robinson CJ, Mulloy B, Gallagher JT, Stringer SE. VEGF165-binding sites within heparan sulfate encompass two highly sulfated domains and can be liberated by K5 lyase. J Biol Chem. 2006;281(3):1731-40.

35. Ono K, Hattori $H$, Takeshita S, Kurita A, Ishihara M. Structural features in heparin that interact with VEGF165 and modulate its biological activity. Glycobiology. 1999;9(7):705-11.

36. Esko JD, Lindahl U. Molecular diversity of heparan sulfate. J Clin Invest. 2001; 108(2):169-73
37. Lamanna WC, Frese M-A, Balleininger M, Dierks T. Sulf loss influences N-, 2O-, and 6-O-sulfation of multiple heparan sulfate proteoglycans and modulates fibroblast growth factor signaling. J Biol Chem. 2008;283(41): 27724-35.

38. Otsuki S, Taniguchi N, Grogan SP, D'Lima D, Kinoshita M, Lotz M. Expression of novel extracellular sulfatases Sulf-1 and Sulf-2 in normal and osteoarthritic articular cartilage. Arthritis Res Ther. 2008;10(3):R61.

39. Otsuki S, Hanson SR, Miyaki S, Grogan SP, Kinoshita M, Asahara H, et al. Extracellular sulfatases support cartilage homeostasis by regulating BMP and FGF signaling pathways. Proc Natl Acad Sci U S A. 2010;107(22): 10202-7.

40. Otsuki S, Murakami T, Okamoto Y, Hoshiyama Y, Oda S, Neo M. Suppression of cartilage degeneration by intra-articular injection of heparan sulfate 6-O endosulfatase in a mouse osteoarthritis model. Histol Histopathol. 2017; 32(7):725-33.

41. Nandini CD, Mikami T, Ohta M, Itoh N, Akiyama-Nambu F, Sugahara K. Structural and functional characterization of oversulfated chondroitin sulfate/dermatan sulfate hybrid chains from the notochord of hagfish. Neuritogenic and binding activities for growth factors and neurotrophic factors. J Biol Chem. 2004;279(49):50799-809.

42. Li F, Nandini CD, Hattori T, Bao X, Murayama D, Nakamura T, et al. Structure of pleiotrophin- and hepatocyte growth factor-binding sulfated hexasaccharide determined by biochemical and computational approaches. J Biol Chem. 2010;285(36):27673-85.

43. Isemura M, Sato N, Yamaguchi Y, Aikawa J, Munakata H, Hayashi N, et al. Isolation and characterization of fibronectin-binding proteoglycan carrying both heparan sulfate and dermatan sulfate chains from human placenta. J Biol Chem. 1987;262(18):8926-33.

44. Kokenyesi R, Silbert JE. Formation of heparan sulfate or chondroitin/ dermatan sulfate on recombinant domain I of mouse perlecan expressed in Chinese hamster ovary cells. Biochem Biophys Res Commun. 1995;211(1):262-7.

45. Brown JC, Sasaki T, Göhring W, Yamada Y, Timpl R. The C-terminal domain V of perlecan promotes beta1 integrin-mediated cell adhesion, binds heparin, nidogen and fibulin-2 and can be modified by glycosaminoglycans. Eur J Biochem. 1997;250(1):39-46.

46. Bernfield M, Kokenyesi R, Kato M, Hinkes MT, Spring J, Gallo RL, et al. Biology of the syndecans: a family of transmembrane heparan sulfate proteoglycans. Annu Rev Cell Biol. 1992;8:365-93.

47. Gopal S, Bober A, Whiteford JR, Multhaupt HAB, Yoneda A, Couchman JR. Heparan sulfate chain valency controls syndecan-4 function in cell adhesion. J Biol Chem. 2010;285(19):14247-58.

48. Yamada S, Sugahara K. Potential therapeutic application of chondroitin sulfate/dermatan sulfate. Curr Drug Discov Technol. 2008;5(4):289-301.

49. Eriksson AS, Spillmann D. The mutual impact of syndecan-1 and its glycosaminoglycan chains--a multivariable puzzle. J Histochem Cytochem. 2012;60(12):936-42.

50. Deepa SS, Yamada S, Zako M, Goldberger O, Sugahara K. Chondroitin sulfate chains on syndecan-1 and syndecan-4 from normal murine mammary gland epithelial cells are structurally and functionally distinct and cooperate with heparan sulfate chains to bind growth factors. A novel function to control binding of midkine, pleiotrophin, and basic fibroblast growth factor. J Biol Chem. 2004:279(36):37368-76.

\section{Publisher's Note}

Springer Nature remains neutral with regard to jurisdictional claims in published maps and institutional affiliations.

Ready to submit your research? Choose BMC and benefit from:

- fast, convenient online submission

- thorough peer review by experienced researchers in your field

- rapid publication on acceptance

- support for research data, including large and complex data types

- gold Open Access which fosters wider collaboration and increased citations

- maximum visibility for your research: over $100 \mathrm{M}$ website views per year

At $\mathrm{BMC}$, research is always in progress.

Learn more biomedcentral.com/submissions 